\title{
OPTIMAL CONTROL STRATEGY BASED MULTILEVEL MATRIX CONVERTER FOR WIND POWER GENERATION SYSTEM
}

\author{
Shivani Johri, Vinod kumar, Shripati Vyas \\ E-Mail Id: sjohri07@gmail.com, vinodcte@yahoo.co.in, shripatiphd2018@gmail.com \\ Department of Electrical Engineering, College of Technology and Engineering, Udaipur, India
}

\begin{abstract}
This paper presents the development of an optimal control strategy for performance enhancement in DFIG based wind generation system in simulation environment to validate the performance of control strategy through simulation under balanced and unbalanced conditions. A laboratory prototype of $2.2 \mathrm{KW}$ of multilevel matrix converter-based wind generation system is set up to validate the effects under different inputs /outputs. The control system is implemented on a DSpace DS1104 real time board. As in order to get satisfying output and to obtain efficient good amount of power quality, it is necessary to investigate and develop wind turbine generator systems (WTGS). An optimal control strategy for performance enhancement and efficiency optimization is developed and implemented with FLC.
\end{abstract}

Keywords: Multilevel matrix converter, wind turbine emulator, wind energy conversion system (WECS), doubly fed induction generator (DFIG)

\section{INTRODUCTION}

Winds are caused by the unevenness of the Earth's surface, asymmetric heating of atmosphere by the Sun along with rotation of Earth. Different surfaces of Earth absorb the Sun's heat at differences and ultimately results in wind differences. The warm air above land rises and expands. Heavier air rushes to take its place ultimately creating winds. This happens in day and night time, wind reverses because air cools faster than land over water. Wind energy has different aspects to be more productive such as intermittency is not easy to handle as variations in wind speeds causes rotor to run at varying velocities. Another is efficiency, for maximum efficiency blade should move with uniform velocity and absolute velocity of blade should be equal to relative velocity of blade [1][2]. According to EIA, in 2019 a total of $10.9 \mathrm{GW}$ capacity is currently expected to come online. Illinois, Texas and Iowa would be covering more than half of 2019 with addition of wind energy capacity. According to statistics of EIA generated on Jan 10,2019, wind energy would cover $46 \%$ of planned additions [3].

National Gas, Coal, Petroleum and some fuels have been the prime sources for generation of electric power. But World is facing a gap between demand and supply of electrical power. In order to meet this situation, a number of solutions are there in which wind energy has grabbed much attention due to possessing of being a quality of promising one. Interest of wind energy as electric power generating source has grown in recent years due to many reasons [4][5].

DFIG is taken as main component in the paper because of reduced mechanical stress, its power conversion capability at varying wind speed and low price These useful, economic and technical characteristics have uplifted the commercialization of DFIG based wind generation system (WGS). The performance of DFIG based WGS depends on power electronic converters implemented on both grid and rotor side. MMC in wind energy systems is most promising one due to their modularity and capability to reach high nominal volume. So, use of advantages of both multilevel (high volume is get by low volume rating devices) and matrix converter (AC-AC conversion circuits with bi-directional conductive and bi-directional blocking switcher) with variable voltage range along with different switching states will be used in this paper for WGS with DFIG [7].

\section{PROPOSED MMC INTERFACED DFIG BASED WECS}

Fig. 2.1 presents a schematic of DFIG where stator is directly connected to the grid (through a coupling reactance) while the connection between the rotor and the grid is made through an electronic power regulated system, composed of power electronic converter i.e. MMC. There are three parameters of DFIG that can be controlled which are rotor current amplitude, rotor current frequency and rotor current phase. The stator winding is connected directly to the $50 \mathrm{~Hz}$ grid while the rotor is fed at variable frequency through the MMC. Using the parameters of equivalent step-up transformer and the equivalent collector network, the output power of the equivalent DFIG, $V_{g}, I_{g}, P_{g}$ can be calculated. The variable voltage $V_{r s c}$ at the frequency $f_{r}$ on the rotor side is converted by the MMC to the electric power compatible to the grid voltage of $\mathrm{V}_{\mathrm{gsc}}$ at the constant frequency $\mathrm{f}_{\mathrm{g}}$. 


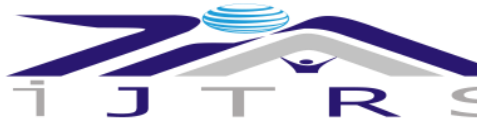

International Journal of Technical Research \& Science

The stator current is regulated by controlling the output current from the rotor PEC. It is assumed that the voltage drop across the stator resistance and the leakage reactance is negligible. The DFIG stator side voltage $\mathrm{V}_{\mathrm{s}}$ and the frequency $f_{s}$ match the grid voltage $V_{g s c}$ and the grid frequency $f_{g}$. But the rotor side PEC voltage $V_{\text {rsc }}$ and frequency $\mathrm{f}_{\mathrm{r}}$ do not match the grid side PEC voltage and frequency.

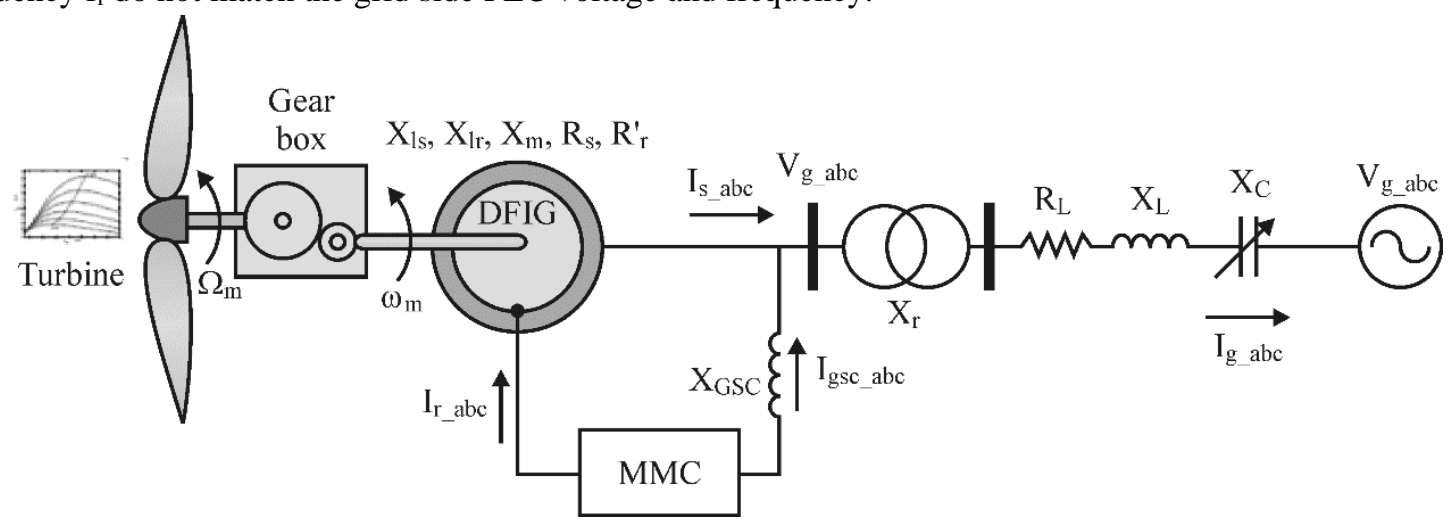

Fig. 2.1 Proposed MMC interfaced DFIG based WECS

The mechnical power and the startor electric power output are computed as follows:

$$
\begin{aligned}
& P_{m}=T_{m} \omega_{r} \\
& P_{s}=T_{e m} \omega_{s}
\end{aligned}
$$

For a loss less generator the mechanical equation is:

$$
\mathrm{J} \frac{\mathrm{d} \omega_{\mathrm{r}}}{\mathrm{dt}}=\mathrm{T}_{\mathrm{m}}-\mathrm{T}_{\mathrm{em}}
$$

In steady-state at fixed speed for a loss less generator $T_{m}=T_{e m}$ and $P_{m}=P_{s}+P_{r}$ it follows that:

$$
P_{r}=P_{m}-P_{s}=T_{m} \omega_{r}-T_{e m} \omega_{s}=-T_{m}\left(\frac{\omega_{s}-\omega_{r}}{\omega_{s}}\right) \omega_{s}=-s T_{m} \omega_{s}=-s P_{s}
$$

Where $\mathrm{s}$ is defined as the slip of the generator:

$$
\mathrm{s}=\frac{\omega_{\mathrm{s}}-\omega_{\mathrm{r}}}{\omega_{\mathrm{s}}}
$$

Where;

$$
\begin{array}{ll}
\mathrm{P}_{\mathrm{m}} & \text { - Mechanical Power capyured by wind turbine and transmitted to the rotor } \\
\mathrm{P}_{\mathrm{s}} & - \text { Stator Electrical power output } \\
\mathrm{P}_{\mathrm{r}} & - \text { Rotor Electrical power output } \\
\mathrm{P}_{\mathrm{gc}} & \text { - Grid converter electrical power } \\
\mathrm{Q}_{\mathrm{s}} & - \text { stator reactive power output } \\
\mathrm{Q}_{\mathrm{r}} & - \text { Rotor reactive power output } \\
\mathrm{Q}_{\mathrm{gc}} & - \text { Grid reactive output power } \\
\mathrm{T}_{\mathrm{m}} & - \text { Mechanical Torque applied to rotor } \\
\mathrm{T}_{\mathrm{em}} & - \text { ElectroMagnetic torque applied to the rotor by the generator } \\
\mathrm{W}_{\mathrm{r}} & - \text { Rotational speed of rotor } \\
\mathrm{W}_{\mathrm{s}} & - \text { Synchronous speed } \\
\mathrm{J} & - \text { Combined rotor and wind turbine inertia coefficient }
\end{array}
$$

Absolute value of slip is lower than 1 and $\mathrm{P}_{\mathrm{r}}$ is only a fraction of $\mathrm{P}_{\mathrm{s}}$. Since $\mathrm{T}_{\mathrm{m}}$ is positive for power generation and since Ws is positive and constant. Pr is positive for negative slip (speed greater than synchronous speed) and it is negative for positive slip (speed lesser than synchronous speed).[7]

\subsection{Wind Turbine Model}

Blades and hub comprise to form turbine. Inputs to the wind turbine are speed of wind, pitch angle, rotor speed and output is mechanical torque. A fraction of wind power that can be extracted by WT is known as aerodynamic power of turbine $\left(\mathrm{P}_{\mathrm{t}}\right)$.[8] This power $\mathrm{P}_{\mathrm{t}}$ can be expressed as: -

$$
\begin{gathered}
\mathrm{P}_{\mathrm{t}}=\tau_{\mathrm{t}} \omega_{\mathrm{t}} \\
=\frac{1}{2} \pi \mathrm{PR}_{\text {blade }}^{2} \mathrm{~V}_{\omega}^{3} \mathrm{C}_{\mathrm{p}}\left(\lambda_{\mathrm{TSR}} \cdot \beta\right)
\end{gathered}
$$

Where;

$$
\begin{array}{lll}
\tau_{\mathrm{t}} & = & \text { Turbine Torque } \\
\mathrm{V}_{\mathrm{w}} & = & \text { Wind Speed }
\end{array}
$$




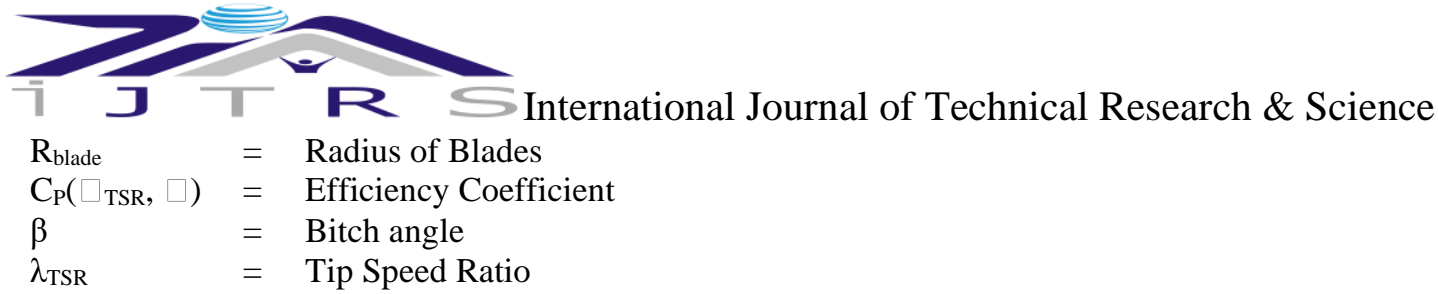

$$
\lambda_{\mathrm{TSR}}=\frac{\mathrm{R}_{\text {blade }} \omega_{\mathrm{t}}}{\mathrm{V} \omega}
$$

Efficiency coefficient is analysed and approximated by a non-linear function: -

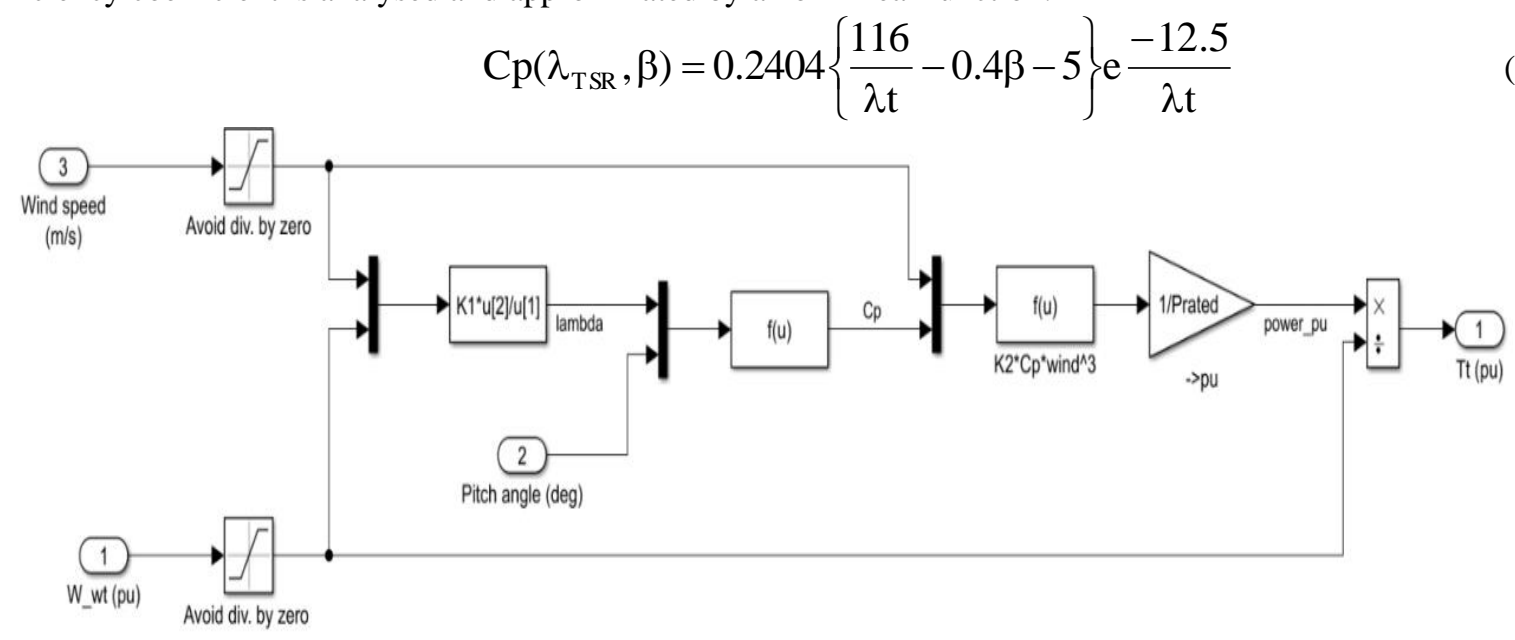

Fig. 2.2 WT Model

\subsection{Configuration of Multilevel Matrix Converter}

Any multilevel converter is based on the idea of creating the additional levels to the supply voltages. If compared with traditional converters, it gives more qualitative output voltage. Along with that, this structure allows various developing models with a high-voltage output using the power switches. The simplified scheme of multilevel matrix converter is shown in Fig. 2.3.

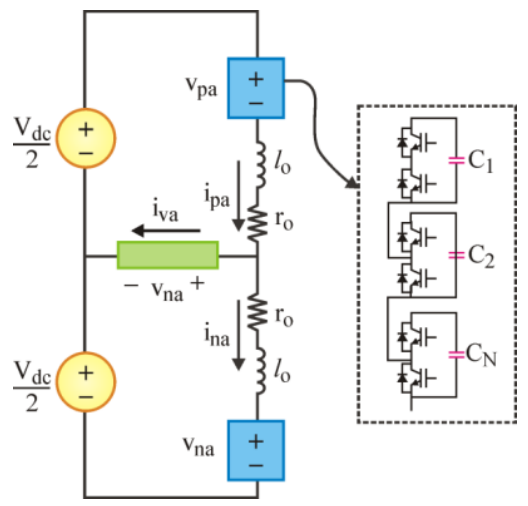

Fig. 2.3 Typical Single Phase Multilevel Matrix Converter

Multilevel Matrix Converter operation can be divided into two operation modes. First where the terminal voltages are generated by the converter with two level switching both sides. Capacitor voltages are regulated to be greater than line to line voltage magnitudes of both sides. Converter are being switched at three voltage line to line voltage level $+\mathrm{V}_{\text {cap }}, 0,-\mathrm{V}_{\text {cap }}$.

Another operation mode is that where converter generates voltage at two level switching at one side and three level switching at other side. The line-to-line voltages of the converter at three level switching with the voltages $+2 \mathrm{~V}_{\text {cap }},+\mathrm{V}_{\text {cap }}, 0,-\mathrm{V}_{\text {cap }},-2 \mathrm{~V}_{\text {cap. }}$ It comprises of anti-parallel diodes and six switches which are organized as voltage source rectifier (VSR). The other series diodes and six switches are organized as current source inverter (CSI). In traditional matrix converter, power flow is from CSI to VSR terminals whereas it has reversed direction of power flow.[9]

Two switches conduct from each upper and lower groups of switches. Two states are formed, one is active state and other is idle state. When two switches are from different phase legs conducts then an active state is formed, whereas idle state is formed when two switches from same phase leg conducts then an idle state is formed. During active state, power is transferred to load, whereas during idle state, current flow within the MMC due to minimization of fictitious de voltage to zero. [10],[11]

Two rules are here to be followed. Input terminals must not be short-circuited as they are connected to voltage sources, Similarly, as output terminals A, B and C are connected to current sources, they must not be opencircuited at any instant. The switching function for each switch is[12]: 
Where;

$$
S_{\mathrm{Kj}}= \begin{cases}1, \text { switch } S_{\mathrm{Kj}} & \text { close } \\ 0, \text { switch } S_{\mathrm{Kj}} & \text { open }\end{cases}
$$

$$
\begin{aligned}
& \mathrm{K}=\{\mathrm{A}, \mathrm{B}, \mathrm{C}\}, \mathrm{j}=\{\mathrm{a}, \mathrm{b}, \mathrm{c}\}, \text { and } \\
& \mathrm{S}_{\mathrm{Ka}}+\mathrm{S}_{\mathrm{Kb}}+\mathrm{S}_{\mathrm{Kc}}=1, \mathrm{~K}=\{\mathrm{A}, \mathrm{B}, \mathrm{C}\}
\end{aligned}
$$

The equation between input and output instantaneous phase voltages is:

$$
\left[\begin{array}{c}
v_{A} \\
v_{B} \\
v_{C}
\end{array}\right]=\left[\begin{array}{lll}
S_{A a} & S_{A b} & S_{A c} \\
S_{B a} & S_{B b} & S_{B c} \\
S_{\mathrm{Ca}} & S_{C b} & S_{C c}
\end{array}\right]\left[\begin{array}{c}
v_{a} \\
v_{b} \\
v_{c}
\end{array}\right]
$$

where $\mathrm{v}_{\mathrm{A}}, \mathrm{v}_{\mathrm{B}}, \mathrm{v}_{\mathrm{C}}\left(\mathrm{v}_{\mathrm{a}}, \mathrm{v}_{\mathrm{b}}, \mathrm{v}_{\mathrm{c}}\right)$ are the output (input) voltages. Line-to-line voltages and phase currents at the output and input terminals respectively are:

$$
\begin{gathered}
{\left[\begin{array}{c}
v_{\mathrm{AB}} \\
v_{\mathrm{BC}} \\
v_{\mathrm{CA}}
\end{array}\right]=\left[\begin{array}{lll}
\mathrm{S}_{\mathrm{Aa}}-\mathrm{S}_{\mathrm{Ba}} & \mathrm{S}_{\mathrm{Ab}}-\mathrm{S}_{\mathrm{Bb}} & \mathrm{S}_{\mathrm{Ac}}-\mathrm{S}_{\mathrm{Bc}} \\
\mathrm{S}_{\mathrm{Ba}}-\mathrm{S}_{\mathrm{Ca}} & \mathrm{S}_{\mathrm{Bb}}-\mathrm{S}_{\mathrm{Cb}} & \mathrm{S}_{\mathrm{Bc}}-\mathrm{S}_{\mathrm{Cc}} \\
\mathrm{S}_{\mathrm{Ca}}-\mathrm{S}_{\mathrm{Aa}} & \mathrm{S}_{\mathrm{Cb}}-\mathrm{S}_{\mathrm{Ab}} & \mathrm{S}_{\mathrm{Cc}}-\mathrm{S}_{\mathrm{Ac}}
\end{array}\right]\left[\begin{array}{l}
v_{\mathrm{a}} \\
\mathrm{v}_{\mathrm{b}} \\
\mathrm{v}_{\mathrm{c}}
\end{array}\right]} \\
{\left[\begin{array}{l}
\mathrm{i}_{\mathrm{a}} \\
\mathrm{i}_{\mathrm{b}} \\
\mathrm{i}_{\mathrm{c}}
\end{array}\right]=\left[\begin{array}{lll}
\mathrm{S}_{\mathrm{Aa}} & \mathrm{S}_{\mathrm{Ba}} & \mathrm{S}_{\mathrm{Ca}} \\
\mathrm{S}_{\mathrm{Ba}} & \mathrm{S}_{\mathrm{Bb}} & \mathrm{S}_{\mathrm{Cb}} \\
\mathrm{S}_{\mathrm{Ac}} & \mathrm{S}_{\mathrm{Bc}} & \mathrm{S}_{\mathrm{Cc}}
\end{array}\right]\left[\begin{array}{l}
\mathrm{i}_{\mathrm{A}} \\
\mathrm{i}_{\mathrm{B}} \\
\mathrm{i}_{\mathrm{C}}
\end{array}\right]}
\end{gathered}
$$

where $v_{A B}, v_{B C}, v_{C A}\left(i_{A}, i_{B}, i_{C}\right)$ are the output instantaneous voltages (currents), and $i_{a}, i_{b}, i_{c}$ are the input instantaneous phase currents. The average equivalents are:

$$
\left[\begin{array}{l}
\tilde{v}_{\mathrm{AB}} \\
\tilde{v}_{\mathrm{BC}} \\
\tilde{v}_{\mathrm{CA}}
\end{array}\right]=\mathrm{D}\left[\begin{array}{c}
v_{\mathrm{a}} \\
v_{\mathrm{b}} \\
v_{\mathrm{c}}
\end{array}\right]
$$

where

$$
\begin{gathered}
\mathrm{D}=\left[\begin{array}{lll}
\mathrm{d}_{\mathrm{Aa}}-\mathrm{d}_{\mathrm{Ba}} & \mathrm{d}_{\mathrm{Ab}}-\mathrm{d}_{\mathrm{Bb}} & \mathrm{d}_{\mathrm{Ac}}-\mathrm{d}_{\mathrm{Bc}} \\
\mathrm{d}_{\mathrm{Ba}}-\mathrm{d}_{\mathrm{Ca}} & \mathrm{d}_{\mathrm{Bb}}-\mathrm{d}_{\mathrm{Cb}} & \mathrm{d}_{\mathrm{Bc}}-\mathrm{d}_{\mathrm{Cc}} \\
\mathrm{d}_{\mathrm{Ca}}-\mathrm{d}_{\mathrm{Aa}} & \mathrm{d}_{\mathrm{Cb}}-\mathrm{d}_{\mathrm{Ab}} & \mathrm{d}_{\mathrm{Cc}}-\mathrm{d}_{\mathrm{Ac}}
\end{array}\right] \\
{\left[\begin{array}{c}
\tilde{\mathrm{i}}_{\mathrm{a}} \\
\tilde{\mathrm{i}}_{\mathrm{b}} \\
\tilde{\mathrm{i}}_{\mathrm{c}}
\end{array}\right]=\left[\begin{array}{lll}
\mathrm{d}_{\mathrm{Aa}} & \mathrm{d}_{\mathrm{Ba}} & \mathrm{d}_{\mathrm{Ca}} \\
\mathrm{d}_{\mathrm{Ab}} & \mathrm{d}_{\mathrm{Bb}} & \mathrm{d}_{\mathrm{Cb}} \\
\mathrm{d}_{\mathrm{Ac}} & \mathrm{d}_{\mathrm{Bc}} & \mathrm{d}_{\mathrm{Cc}}
\end{array}\right]\left[\begin{array}{l}
\mathrm{i}_{\mathrm{A}} \\
\mathrm{i}_{\mathrm{B}} \\
\mathrm{i}_{\mathrm{C}}
\end{array}\right]}
\end{gathered}
$$

Transformation of three-phase variables from abc to dq0 coordinates is given by:

$$
\mathrm{f}_{\mathrm{dq} 0}=\mathrm{T}(\theta) \mathrm{f}_{\mathrm{abc}}
$$

Where;

$$
\begin{aligned}
& f_{d q 0}=\left[\begin{array}{lll}
f_{d} & f_{q} & f_{0}
\end{array}\right]^{T}, \quad f_{a b c}=\left[\begin{array}{lll}
f_{a} & f_{b} & f_{c}
\end{array}\right]^{T} \text {, and } \\
& \mathrm{T}(\theta)=\frac{2}{3}\left[\begin{array}{ccc}
\cos \theta & \cos \left(\theta-\frac{2 \pi}{3}\right) & \cos \left(\theta+\frac{2 \pi}{3}\right) \\
-\sin \theta & -\sin \left(\theta-\frac{2 \pi}{3}\right) & -\sin \left(\theta+\frac{2 \pi}{3}\right) \\
\frac{1}{2} & \frac{1}{2} & \frac{1}{2}
\end{array}\right]
\end{aligned}
$$

Table-2.1 Comparison between Conventional Matrix Converter and MMC

\begin{tabular}{|c|c|c|}
\hline Factor & Conventional Matrix Converter & Multilevel Matrix Converter \\
\hline Voltage conversion ratio & Buck only: & Buck-Boost: \\
\hline$\left(\mathrm{V}_{\text {out }} / \mathrm{V}_{\text {in }}\right)$ & $\mathrm{V}_{\text {out }} \leq 0.866 \mathrm{~V}_{\text {in }}$ & $0 \leq \mathrm{V}_{\text {out }} \leq \mathrm{V}_{\text {in }}$ \\
\hline Switch commutation & Coordination of four-quadrant & Simple transistor plus freewheeling \\
\hline
\end{tabular}


International Journal of Technical Research \& Science

\begin{tabular}{|c|c|c|}
\hline & switches & diode \\
\hline Bus-bar structure & Complex & Modular and simple \\
\hline Multilevel operation & No & Possible \\
\hline Filter elements & AC capacitors and inductors & Inductors \\
\hline
\end{tabular}

\subsection{Development of Control Strategy using Fuzzy Logic Controller}

The main objectives of the fuzzy controllers are to achieve more accurate active and reactive power control of the wind turbine driving the DFIG.Fuzzy Logic controller is able to control complex, uncertain, nonlinear, multivariable time varying and adaptive system such as DFIG. [13][14] The most commonly used fuzzy logic controllers techniques are

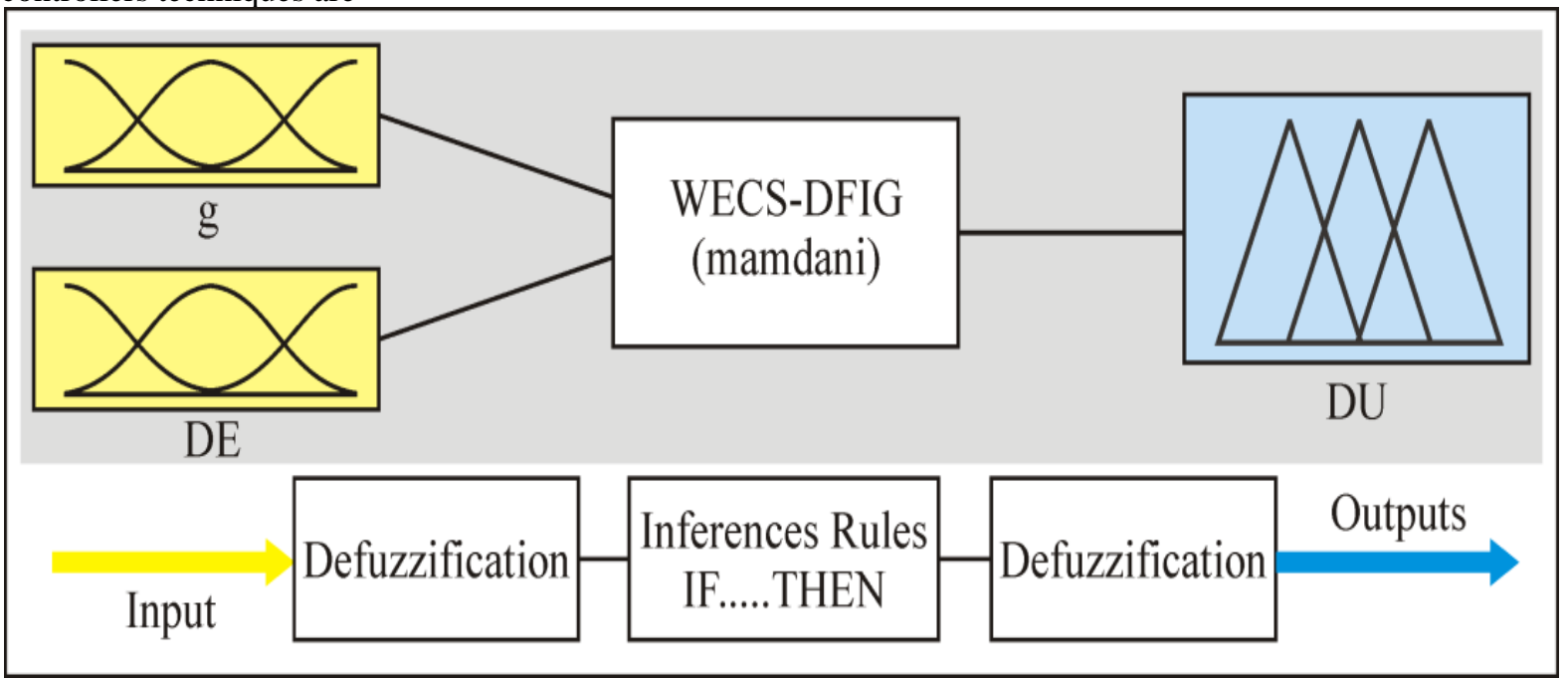

Fig. 2.4 Block Diagram of Fuzzy Control

Fuzzy rule set observe how the output signal can follow the reference value. These rules are designed and applied to fuzzy logic inputs to DFIG wind turbine to reduce output fluctuations along with smoother output signals. [15] Fig. 2.5 shows that output signal and error signal vary with changes in any of two inputs variables.

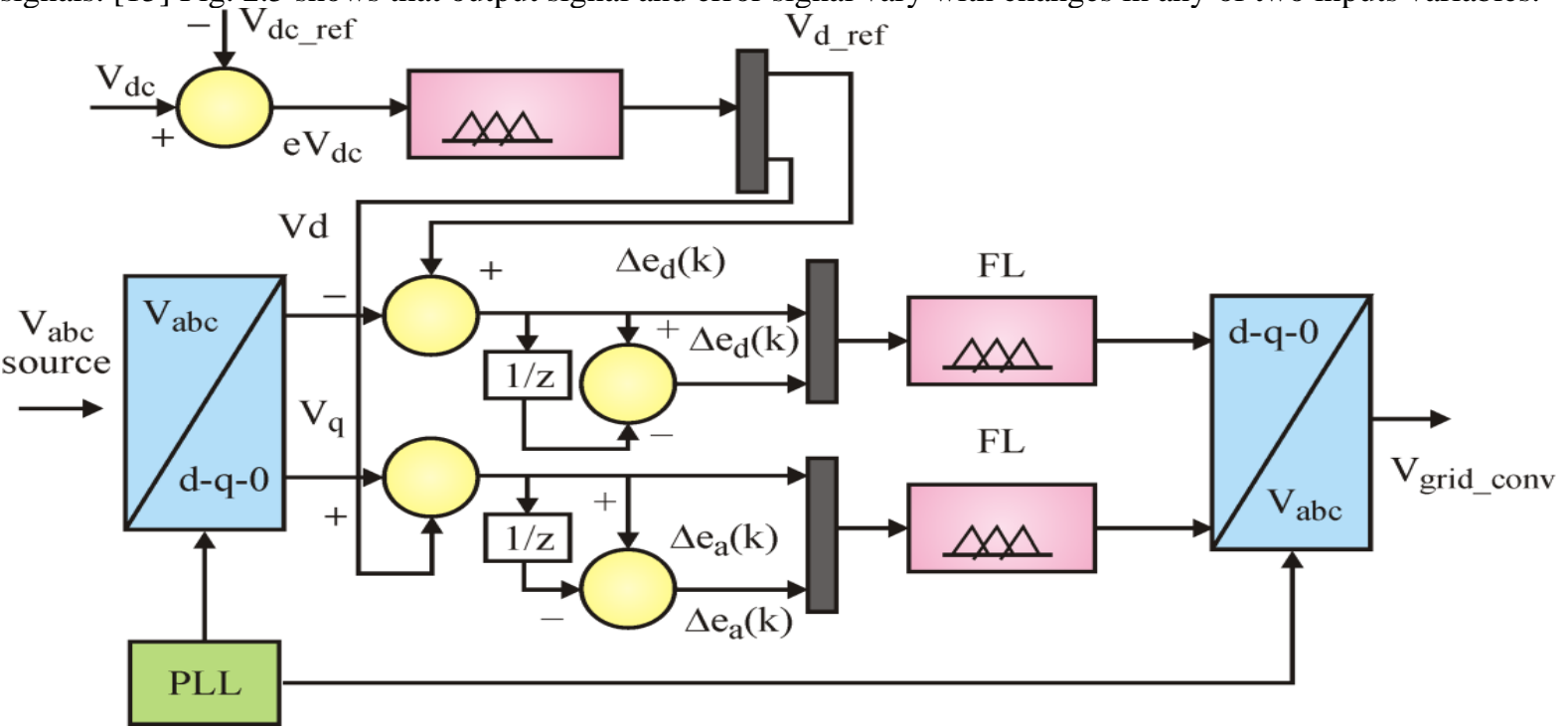

Fig. 2.5 Control Circuit with Fuzzy Logic Controller

\section{RESULTS AND DISCUSSION}

To validate the control strategy through hardware experimentation under different conditions, a laboratory test is carried out on developed $2.2 \mathrm{~kW}$ prototype of DFIG based wind energy conversion system using dSPACE 1104 real time control system interfaced NPC 3-L multilevel matrix converter which is programmed in the MATLAB/Simulink environment. Space vector pulse width modulation-based switching signals are given to the switches of MMC and DC drive-based wind turbine.

The generator output from wind turbine will be controlled using optimally controlled multilevel matrix converter. The dSPACE 1104 kit will be used to implement optimal control and SVM switching code developed in MATLAB $^{\circledR} /$ Simulink. Various parameters like voltage, current, active power, reactive power, total harmonic distortions (THD) for various input/output, balanced/unbalanced and wind conditions will be investigated using power quality analyzer, four channel DSO etc. emulator. Fig. 3.1 illustrates the schematic of laboratory $2.2 \mathrm{KW}$ prototype of proposed matrix converter interfaced wind energy conversion system. 


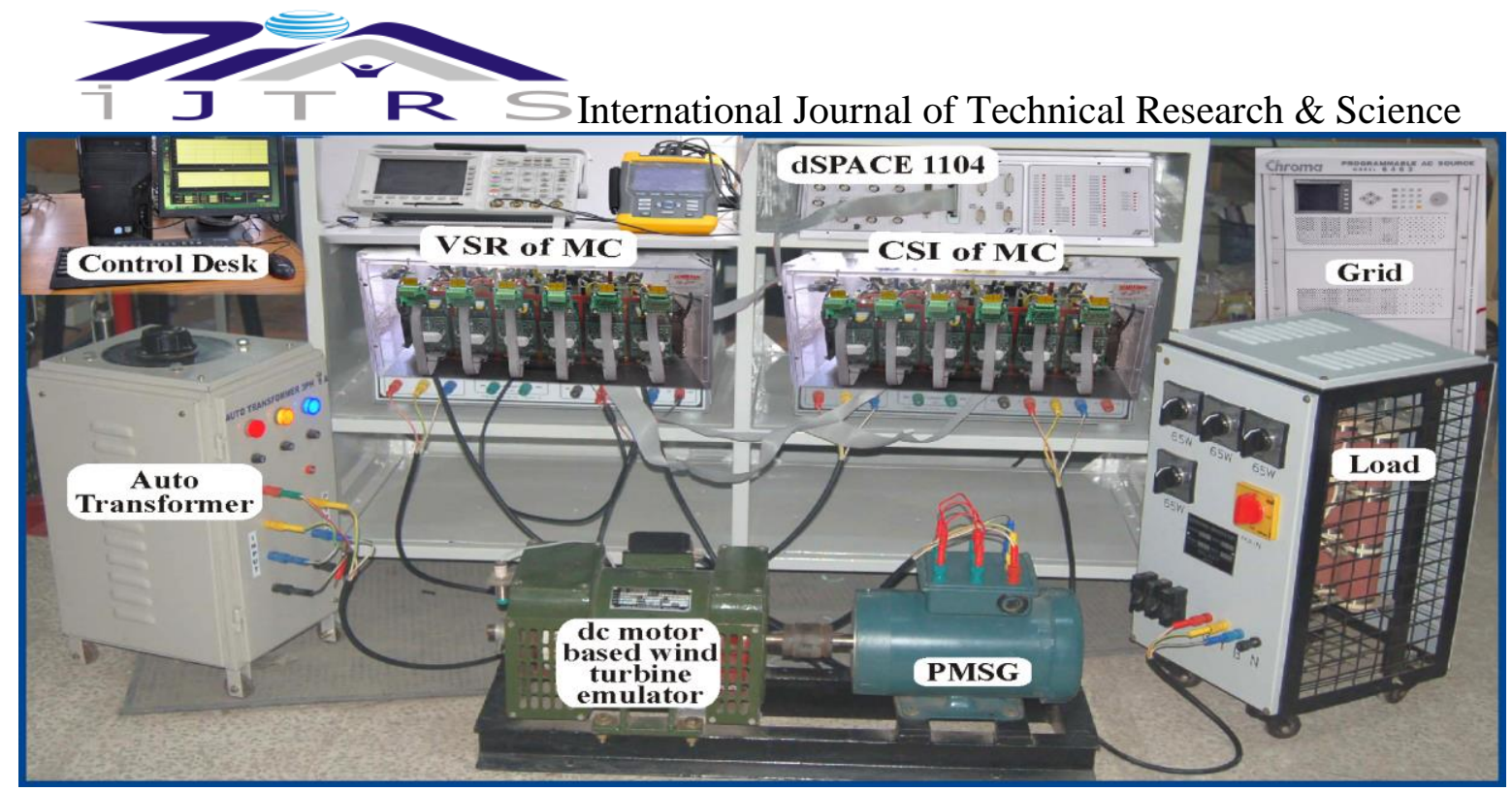

Fig. 3.1 Schematic of the Developed Laboratory Prototype

Simulation responses of the proposed fuzzy logic controlled multilevel matrix converter interfaced DFIG based WECS under various parameters like varying load, variable wind speed, grid voltage sag and swell, three phase and single phase faults conditions using MATLAB/Simulink under different balanced/unbalanced conditions.In first stage, simulations are performed on a conventional converter .In the second stage, a $3-3$ multilevel matrix converter is developed to present the comparative simulation results of developed fuzzy control system with conventional control to validate the operational principles of multilevel matrix converter

\subsection{Response during Constant rated Wind Speed $(12 \mathrm{~m} / \mathrm{s})$ and Resistive Load $(3 \mathrm{KW})$}

This is the first case where constant wind speed of $12 \mathrm{~m} / \mathrm{s}$ is observed for simulation with Resistive load. MATLAB simulation results for the developed DFIG based WECS is shown in Fig. 3.2. As shown in Fig. 3.3, simulation responses of constant wind speed $\left(\omega_{s}\right)$, generator speed $\left(\omega_{m}\right)$, generator output power $\left(P_{a c}\right)$, DFIG phase to phase voltages $\left(\mathrm{V}_{\mathrm{ab}}, \mathrm{V}_{\mathrm{bc}}\right.$ and $\left.\mathrm{V}_{\mathrm{ac}}\right)$ and DFIG phase current are presented. Generated voltage is $230 \mathrm{~V}$ and current is $10.1 \mathrm{~A}$.
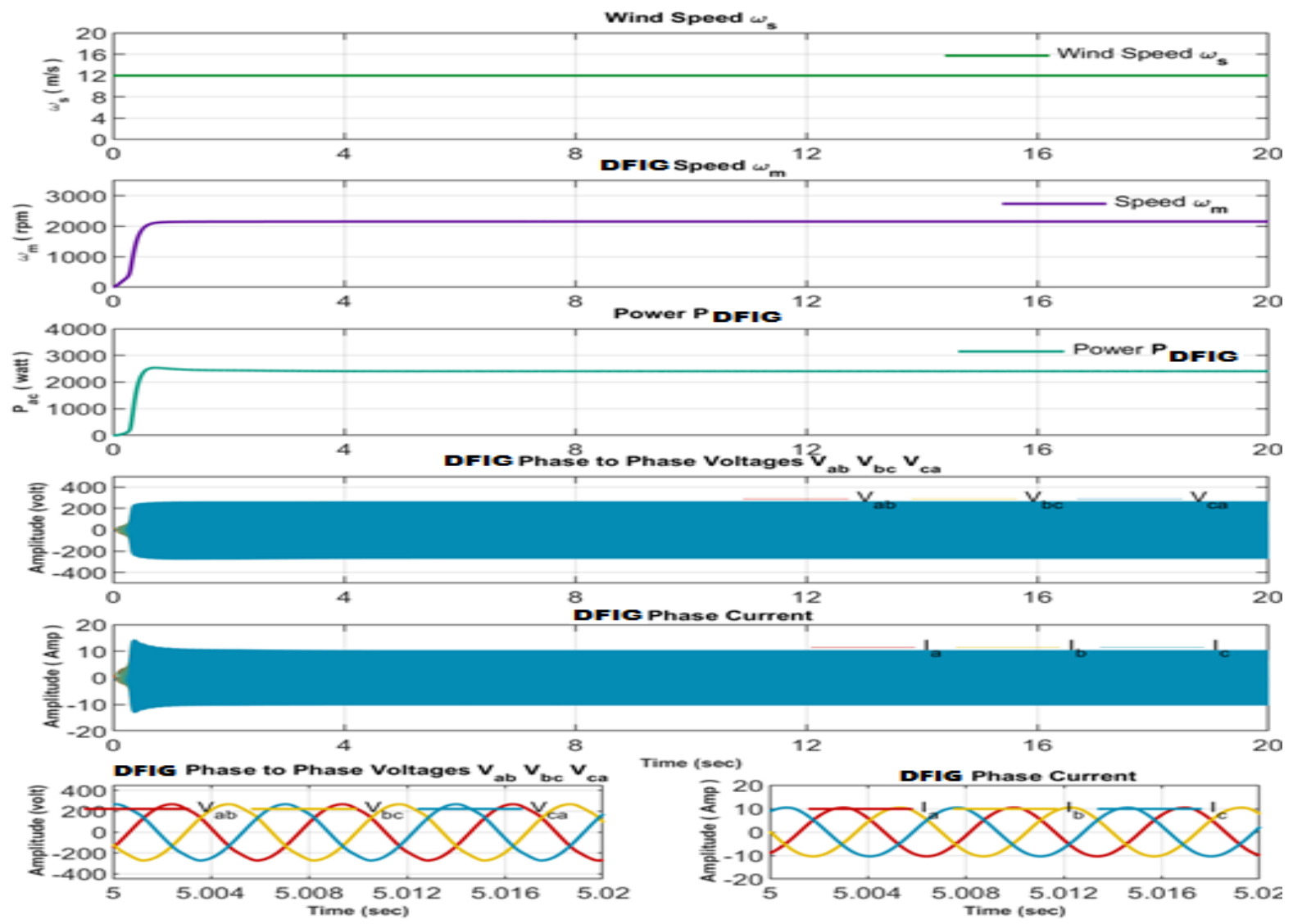

Fig. 3.2 Simulation Results for DFIG based WECS at Constant Wind speed of $12 \mathrm{~m} / \mathrm{s}$, Waveform of Wind Speed $\omega_{s}$, DFIG speed $\omega_{m}$, DFIG Output PowerP PfIG, DFIG phase to phase voltages $V_{a b} V_{b c} V_{c a}$, DFIG Phase Current

DOI Number: https://doi.org/10.30780/IJTRS.V06.I01.004

pg. 6 


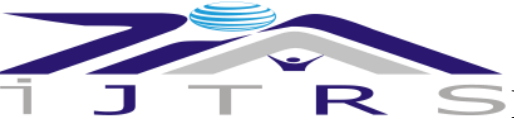

3.2 Response during Impulse Variation of Wind Speed

In the second case, wind speed is varied from $12 \mathrm{~m} / \mathrm{s}$ to $8 \mathrm{~m} / \mathrm{s}$ and again from $8 \mathrm{~m} / \mathrm{s}$ to $12 \mathrm{~m} / \mathrm{s}$ as an impulse function and load is kept constant at $3 \mathrm{KW}$.
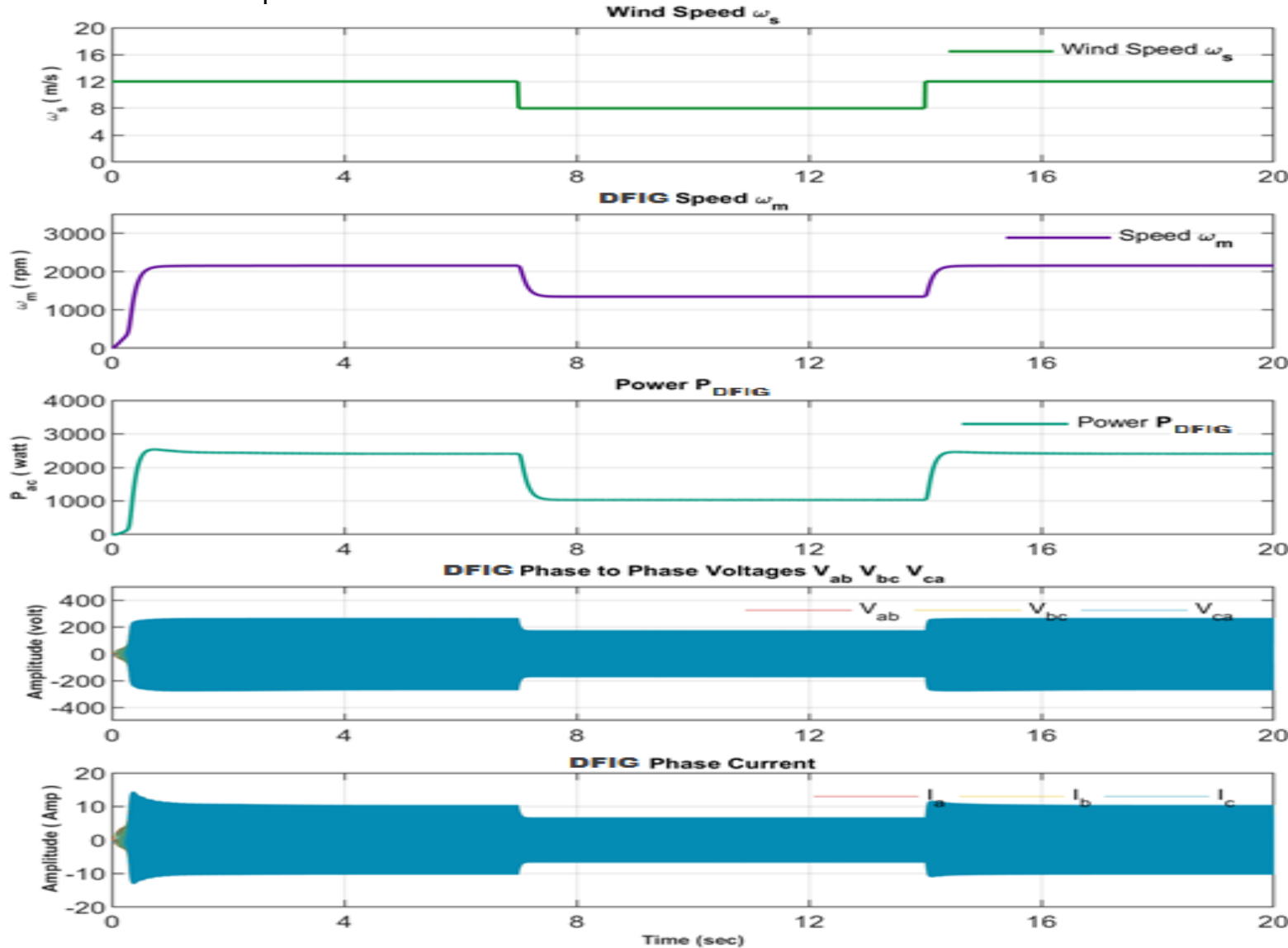

Fig. 3.3 Simulation Waveform of Wind Speed, DFIG Speed, DFIG Output Power, DFIG Phase to Phase Voltages, DFIG Phase Current at during Impulse Variation in Wind Speed from $12 \mathrm{~m} / \mathrm{s}$ to $8 \mathrm{~m} / \mathrm{s}$ to $12 \mathrm{~m} / \mathrm{s}$ with Constant Load

DFIG phase current and DFIG phase to phase voltage is shown and explained. The output voltage and current are sinusoidal in nature during steady-state condition and output voltage is reduced from 280 to $180 \mathrm{~V}$, for time $\mathrm{t}=7$ to $14 \mathrm{sec}$. Similarly, output current reduces from $14.5 \mathrm{~A}$ to $6 \mathrm{~A}$, after $\mathrm{t}=14 \mathrm{sec}$.
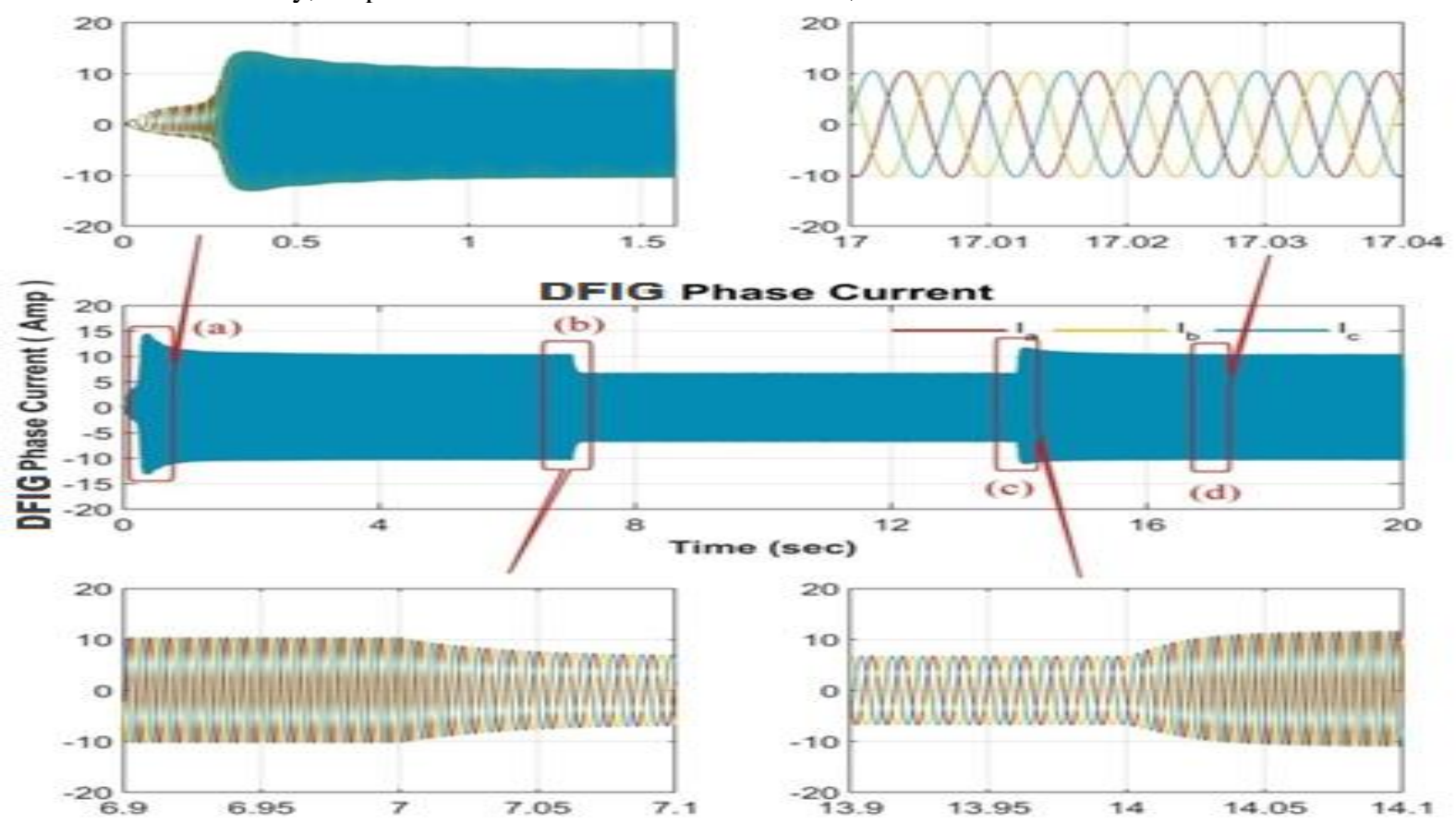

Fig. 3.4 Simulation Waveform of DFIG Phase Current and DFIG Phase to Phase Voltage at during Impulse Variation in Wind Speed from $12 \mathrm{~m} / \mathrm{s}$ to $8 \mathrm{~m} / \mathrm{s}$ to $12 \mathrm{~m} / \mathrm{s}$ with Constant Load 


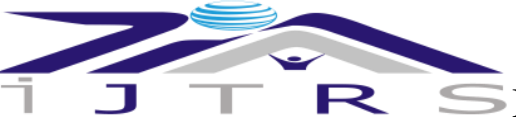

Simulation responses of both torque (Electro-magnetic and mechanical) generator RMS output voltage, generator output current, generator voltage, generator current is shown in fig.3.5.

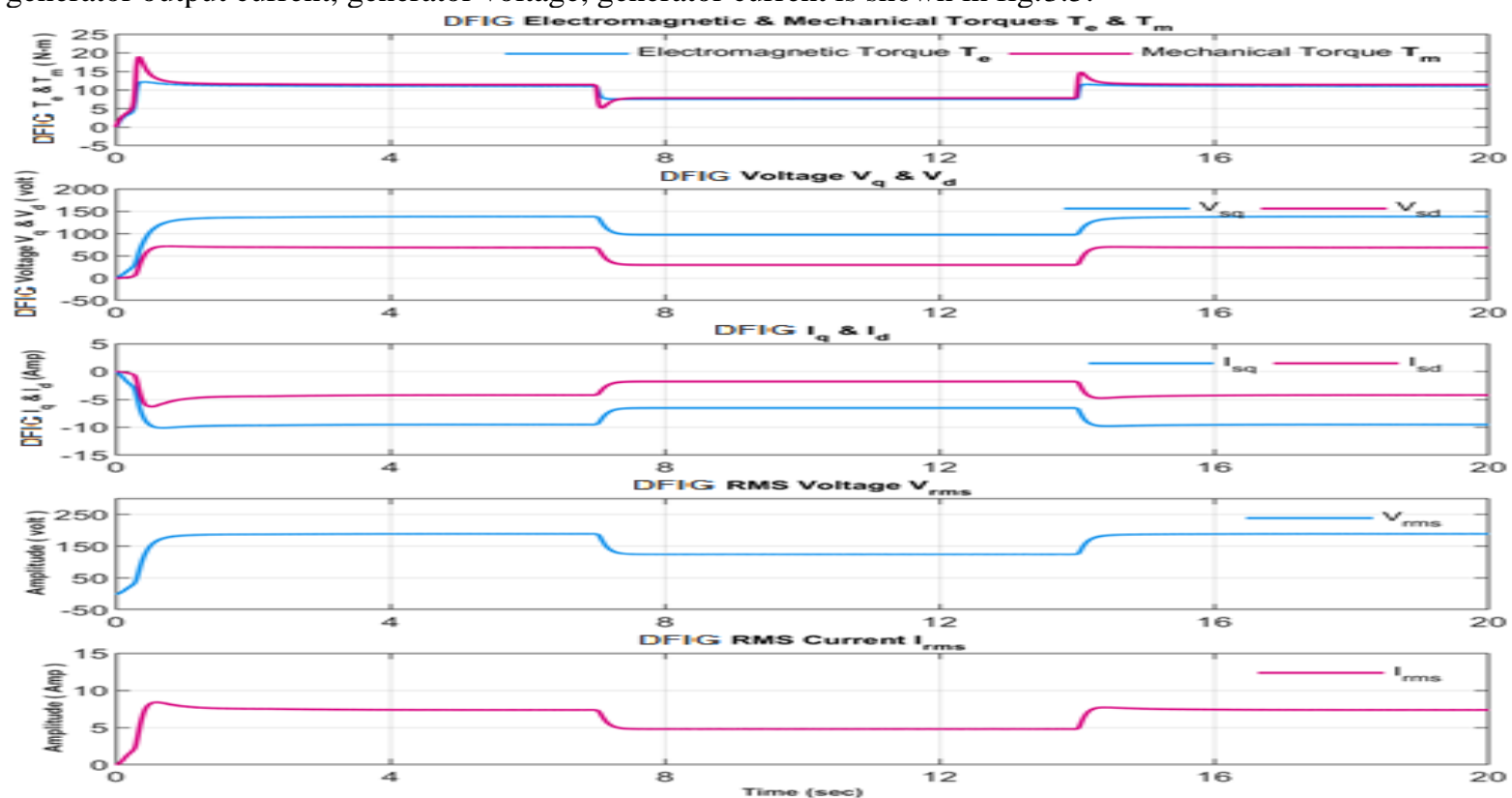

Fig. 3.5 Simulation Waveform of Electromagnetic and Mechanical Torque, DFIG Voltage, DFIG

Current, DFIG Rms Output Voltage and DFIG RMS Output Current at During Impulse Variation in Wind Speed From 12 M/S To 8 M/S To 12 M/S With Constant Load

\subsection{Response during System Fault Condition}

There are various fault conditions, phase to ground fault conditions always cause voltage sags and voltage dips in the system. These are for vary short duration of approximately $.02 \mathrm{sec}$ near the grid. Fault period for three phase short circuit is very important to examine fault ride through (FRT) capabilities of developed system, Fig. 3.6 shows the simulation result for grid voltage and current, grid active and reactive power, fictious D.C and generator speed for all the three types of fault.
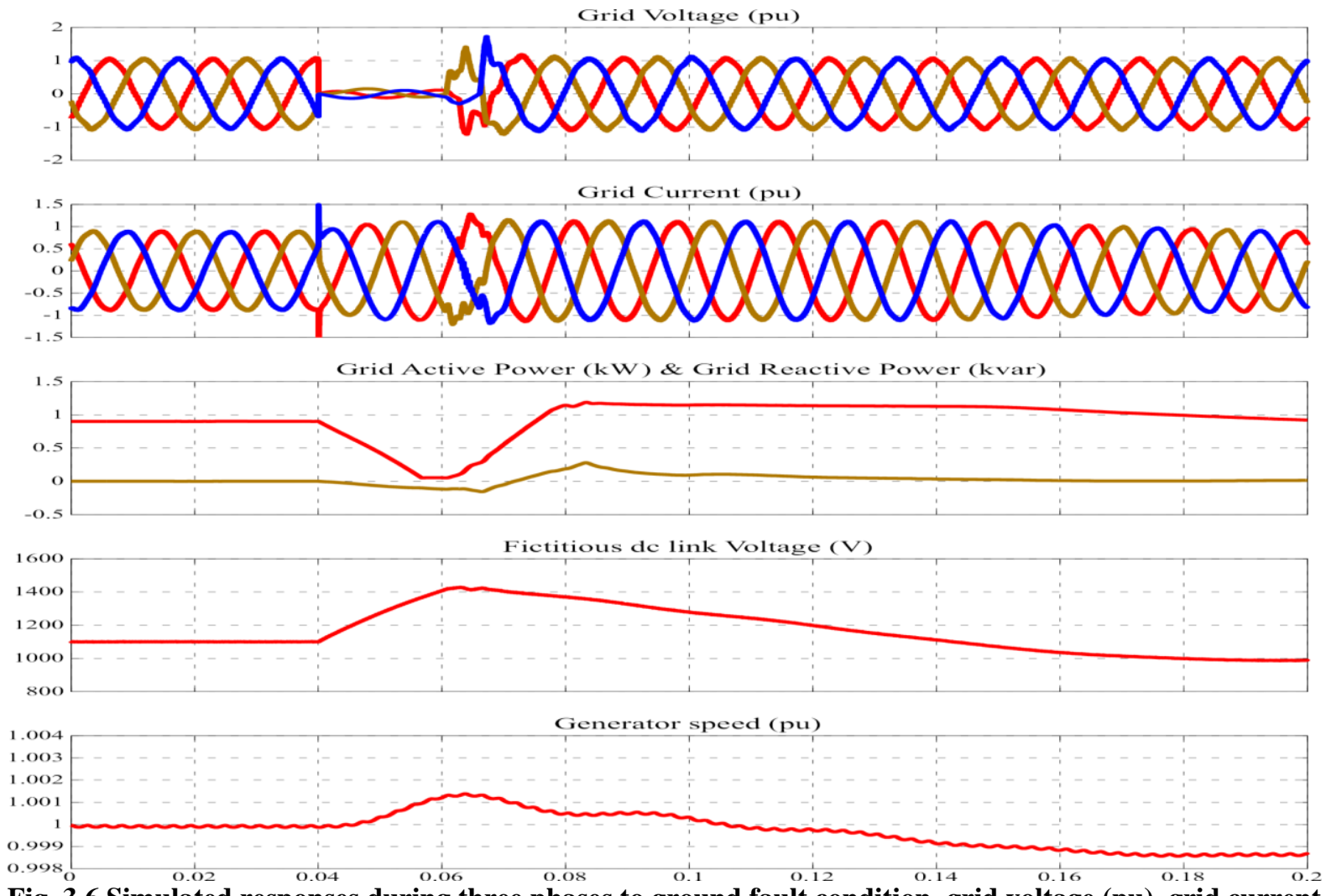

Fig. 3.6 Simulated responses during three phases to ground fault condition, grid voltage (pu), grid current (pu), grid active power $(\mathrm{kW})$ and grid reactive power (kvar), fictitious dc link voltage (V), generator speed (pu)

DOI Number: https://doi.org/10.30780/IJTRS.V06.I01.004

pg. 8 


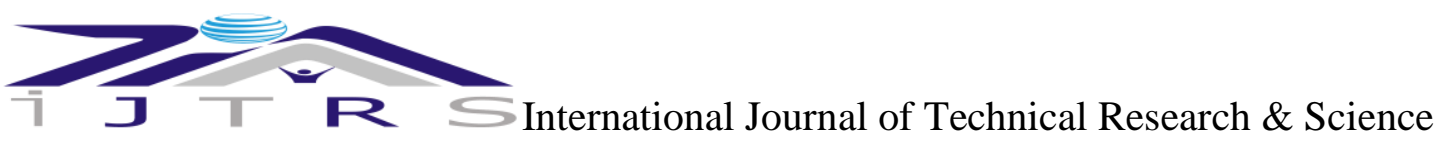

Grid Voltage (pu)
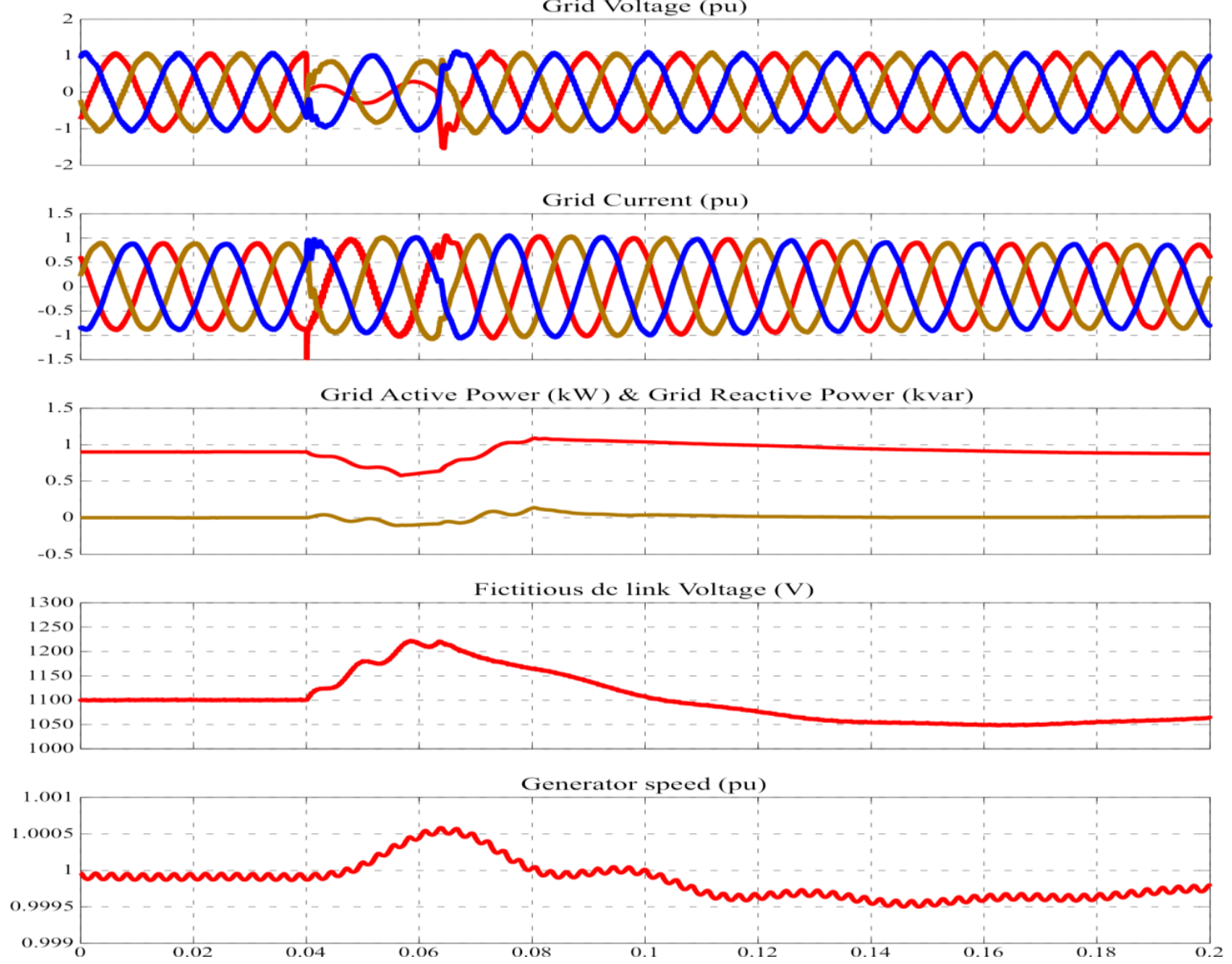

Fig. 3.7 Simulated responses during single phase to ground fault. Grid voltage (pu), grid current (pu), grid active power $(\mathrm{kW})$ and grid reactive power (kvar), fictitious dc link voltage $(\mathrm{V})$, generator speed $(\mathrm{pu})$ The developed fuzzy control system observes the optimum blocking period for the serious fault such as $0.2 \mathrm{~ms}$ for single phase and $15 \mathrm{sec}$ for three phase faults. The grid frequency in the wind turbine is negligibly affected by fault along with the constant grid voltage. Grid code requirements are met by using proposed strategy and small voltage dips recovers in $0.35 \mathrm{sec}$.

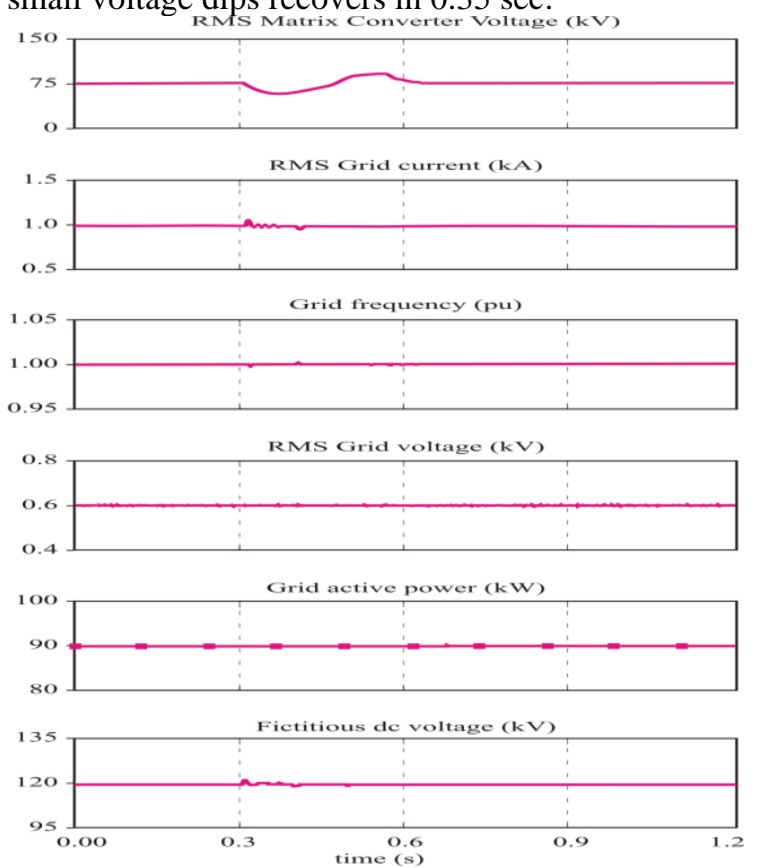

(a) With proposed control

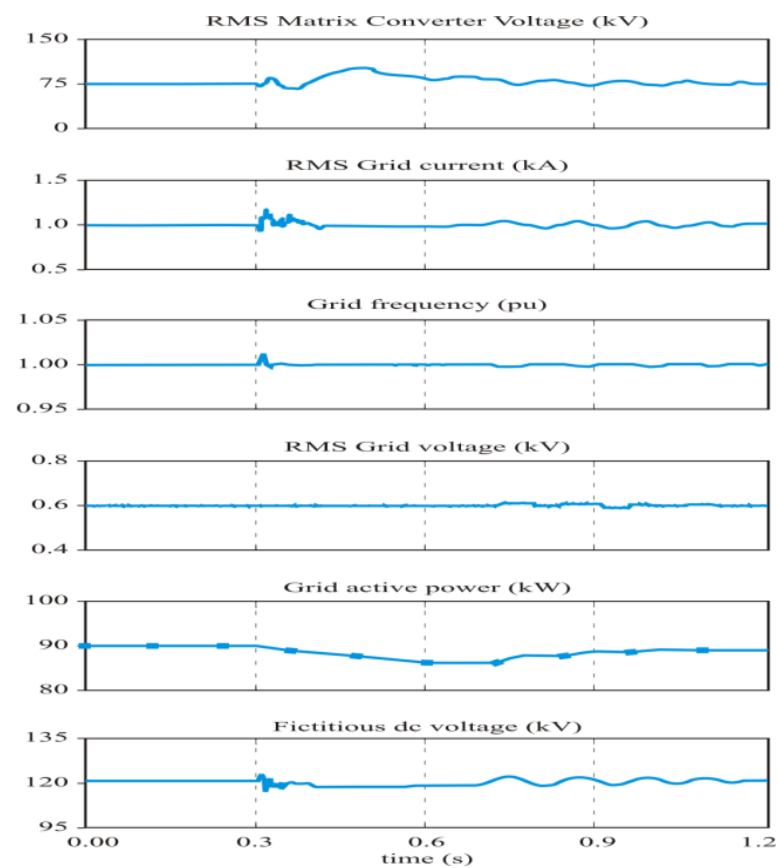

(b) With conventional control

Fig. 3.8 Simulated response of the proposed MC interfaced WECS under single- phase fault with (a) proposed control, and (b) conventional control. (Where waveforms are of RMS matrix converter voltage,

RMS grid current, grid frequency, grid voltage, grid active power, and fictitious dc link voltage) 


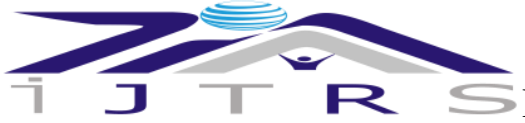

\subsection{Response during Varying Load Condition}

When load is varied from half load to full load, controller maintain load voltage constant and during variation from full load to half load a control action is needed to maintain load voltage at constant magnitude. In the first case load current is increased and in the later one load current is decreased.

During this process developed fuzzy controller maintain the output current of MMC to regulate load voltage. The developed control strategies also evaluate the disturbance rejection capability as we compare both conventional control and proposed control superiority of proposed control over conventional control is validated as traditional control method is not able to mitigate any fluctuation during change in load conditions.

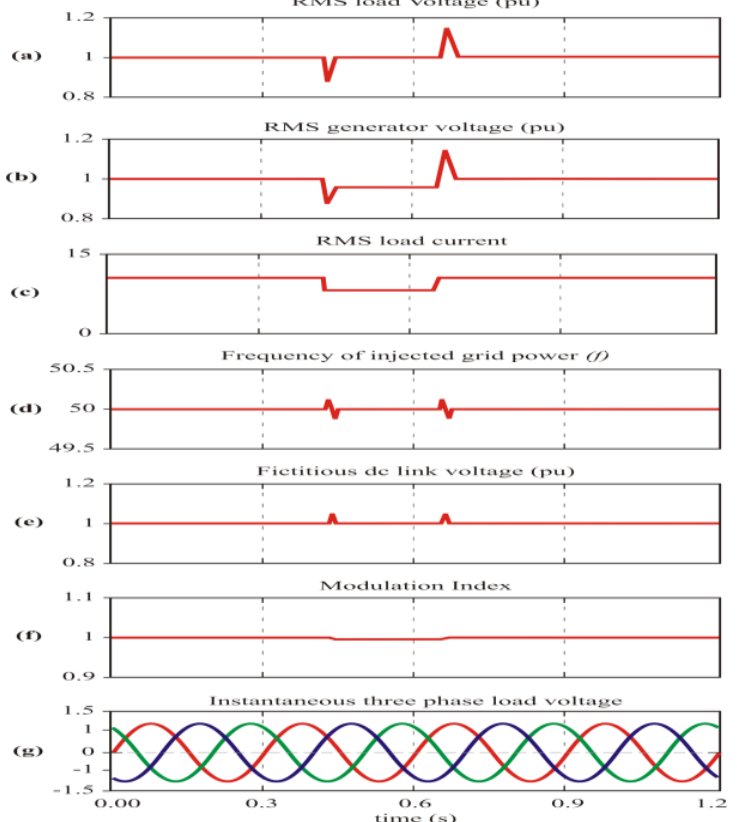

A. With proposed control

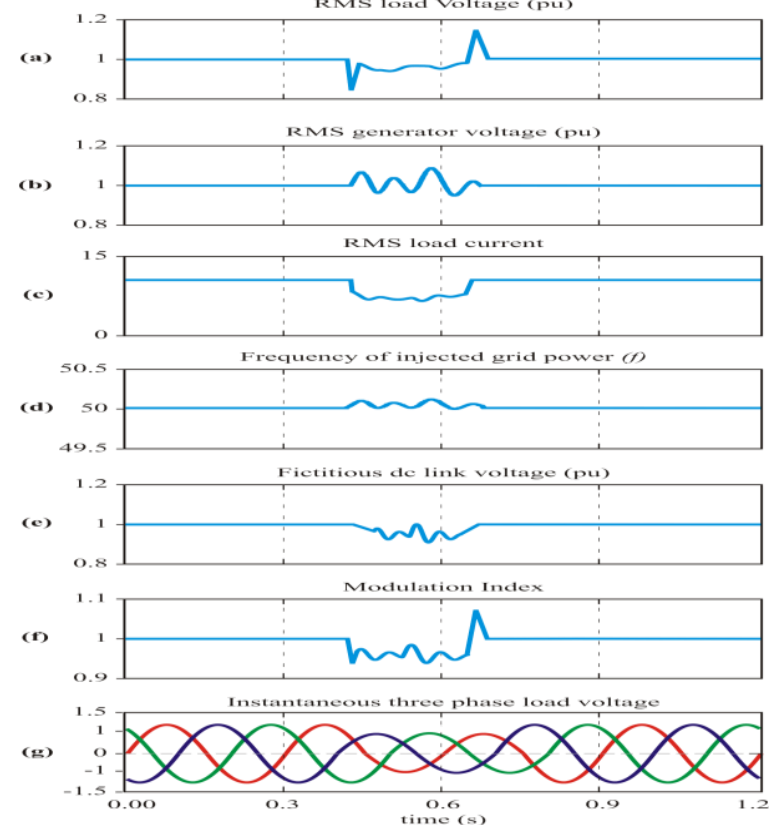

B. With conventional control

Fig. 3.9 Simulated waveform during varying load condition. (A) Proposed control; and (B) conventional control, (where (a) RMS load voltage, (b) RMS generator voltage; (c) RMS load current; (d) frequency;

(e) fictitious dc link voltage; (f) modulation index; and (g) Instantaneous three phase grid voltage

For both balance and unbalance condition proposed control strategy of MMC proves that it can maintain unity power factor even in the case of variable and fluctuating frequency or voltage at generator terminals. Adding on to this it results in more output power and complements the reactive power requirements of the DFIG. One more advantage of the developed system is that it recovers back very quickly during stress on electrical components and stabilize the load frequency and voltage by controlling modulation index of MMC proposed and developed control strategy observe better performance both steady states according to simulation results.

\section{CONCLUSION}

The modelling implemented investigates the dynamic steady state analysis of MMC based DFIG for wind turbine. The modelled DFIG with MMC is further tested for real time performance evaluation for active and reactive power for a various range of wind and generator speeds for balanced as well as unbalanced conditions at different values of voltages and currents are compared with the results obtained from laboratory setup. Implementation of complete setup in MATLAB $® /$ Simulink $®$ provides flexibility of changing the operational as well as system parameters during on rum environment.

Fuzzy Logic Controller approach for MMC based DFIG is derived and fulfills the need of better performance than conventional PI controllers. Following observations have been recorded:

$>$ Input Filters for multilevel matrix converter system mitigated lower harmonic components. Harmonic balanced has been created by reducing the ripple component of input current and voltage waveforms.

$>$ Proposed approach also maintains higher power factor at input resulting wider control range of FLC based multilevel matrix converter.

$>$ This approach derives a complete steady state analysis where system operates at various variable parameters under balanced and unbalanced condition and varying loads. This steady state analysis also defines stability of the system and shows that stable responses are affected by different system parameters.

$>$ Simulation and experimental results verify the robustness of proposed controller for varying loads and rotor speeds. This presents a balanced set of output voltages with desired magnitude and frequency. 
J T R SInternational Journal of Technical Research \& Science

> This control strategy improves efficiency reduces balanced power harmonics, voltage harmonics and current harmonics, improves the output power, minimize ripple in output power.

$>$ At higher speed of rotor, reactive power generation capacity is limited by rotor currents and at low rotor speed reactive power generation capacity is limited by rotor voltage. So, here the reactive power capability of DFIG gets improved by proposed control strategy.

$>$ This approach also provides a considerable contribution to grid voltage support during decrease in wind speed fluctuations or short circuit periods.

$>$ From experimental and simulation results, it can be verified that DFIG has an equilibrium in output voltage and current, reduced power losses.

\section{REFERENCES}

[1] Stirling, W. Wind-driven generators Published in: Journal of the Institution of Electrical Engineers 61, 323, October 1923 pp. 1096 - 1099.

[2] Jaya Devaiah , T.S. ; Richatd T. Smith Generation Schemes for Wind Power Plants Published in: IEEE Transactions on Aerospace and Electronic Systems AES-11, Issue: 4 , July 1975, pp 543 - 550.

[3] Earnest, J. and Wizelius, T. Wind Power Plants and Project Development. New Delhi, India: PHI Learning, May 2011.

[4] Hu, J., Nian, H., et al.: 'Dynamic Modeling and Improved Control of DFIG Under Distorted Grid Voltage Conditions', IEEE Transactions on Energy Conversion, 26(1), March 2011, pp. 163 - 175.

[5] Pena, R., Clare, J.C. et al.: 'Doubly fed induction generator using back-to-back PWM converters and its application to variable Speed Wind Energy Generation', IEE Proceedings - Electric Power Applications, 143 (3), May 1996 pp. $231-241$.

[6] Craig C. Johnson, Economical Design of Wind Generating Plants Published in: IEEE Transactions on Aerospace and Electronic Systems AES-12:3, May 1976) pp 316 - 320.

[7] Abbey, C., et al.: 'Modeling Requirements for Transient Stability Studies for Wind Parks' IEEE Power Engineering Society General Meeting. Montreal, Que., Canada, October 2006, pp:345.

[8] Malik E., et al.: 'A Complete Modeling and Simulation of Induction Generator Wind Power Systems, 2010 IEEE Industry Applications Society Annual Meeting, Houston, TX, USA. Nov. 2010.

[9] Herrera, L. Modelling and Circulating Current Control of MMC. IEEE Applied Power Electronics Conference and Exposition (APEC), Charlotte, NC, USA. 2015;2898-2902.

[10] Wang, J. High-Power Multi-Modular Matrix Converters with Sinusoidal Input/output Waveforms. 35th Annual Conference of IEEE Industrial Electronics, Porto, Portugal. 2010.

[11] Sun, Y. A Direct Control Algorithm for Cascaded H-bridge Multilevel Matrix Converter. IEEE 2nd International Future Energy Electronics Conference (IFEEC), Taipei, Taiwan. 2015.

[12] Erickson, R.W., Al-Naseem, O.A. A New Family of Matrix Converters IECON'01. 27th Annual Conference of the IEEE Industrial Electronics Society (Cat. No.37243). 2001; pp. 1515-1520.

[13] Wang, L. and Truong, D.-N., 'Stability Enhancement of a Power System with a PMSG-Based and a DFIGBased Offshore Wind Farm Using a SVC with an Adaptive-Network-Based Fuzzy Inference System', IEEE Transactions on Industrial Electronics, 60(7), July 2013, pp.: 2799-2809.

[14] Calvillo, C. F., Martell F., Elizondo, J. L., Ávila A., Macías M. E., Rivera M., Rodriguez J. Rotor, Current Fuzzy Control of a DFIG with an Indirect Matrix Converter.

[15] Kyungbae Yim, and Jaeho Choi, Comparative Study of PI and Fuzzy Controller for Rotor Side Converter of DFIG Fajar Sastrowijoyo, IEEE 7th International Power Electronics and Motion Control Conference ECCE Asia June 2-5, 2012.

[16] Kumar, P., Mathew, L., Shimi, S. L., \& Singh, P. (2016). Need of ICT for Sustainable Development of Power Sector. Proceedings of International Conference on ICT for Sustainable Development, 607614. doi:10.1007/978-981-10-0129-1_63.

[17] Kumar, P., \& Kumar, V. (2020). Energy storage options for enhancing the reliability of Power system in the presence of Renewable Energy Sources. 2020 Second International Conference on Inventive Research in Computing Applications (ICIRCA). doi:10.1109/icirca48905.2020.9183349. 